$A \mathrm{NR} A \mathrm{D}$

Documentos e Debates
Disponível em

http://www.anpad.org.br/rac

RAC, Curitiba, v. 15, n. 2, pp. 338-342, Mar./Abr. 2011

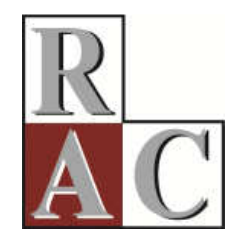

\title{
Réplica 2 - O Que é um Ensaio Teórico? Réplica a Francis Kanashiro Meneghetti
}

\author{
What is a Theoretical Essay? Response to Francis Kanashiro Meneghetti
}

Copyright (C) 2011 RAC. Todos os direitos, até mesmo de tradução, são reservados. É permitido citar parte de artigos sem autorização prévia, desde que seja identificada a fonte. 
A natureza desta seção da RAC é que os autores convidados a escrever réplicas discordem, contra argumentem e se possível tentem invalidar o que foi colocado no documento originalmente proposto ao debate. Devo inicialmente colocar que não serei capaz de me sair a contento desta empreitada pelo fato de que minhas margens de discordância com o autor são relativamente pequenas. Minhas observações seriam no sentido de corroborar e muitas vezes adicionar argumentos a favor dos pontos defendidos. Mas como a vida acadêmica também é debate, vamos adiante acatando as regras do jogo.

Começarei fazendo algumas observações quanto à forma e redação. O título do documento contém um ponto de interrogação. Consequentemente a forma mais adequada de estruturar o documento seria respondendo à pergunta colocada no título. Na verdade, o autor afasta-se deste formato e o resultado é que o trabalho acaba um pouco disperso. Uma sugestão seria primeiramente estender e aprofundar a questão do que seja ensaio teórico. Em segundo lugar, caberia o que, na nossa área de administração e das ciências sociais, se designa por um estado da arte, em que as posições de vários autores, escolas, ou grupos de analistas que se ocuparam do tema são criticamente apresentados. Aqui as observações e contribuições do autor do documento são particularmente importantes, porque já se permite ao leitor vislumbrar posições que serão explicitadas posteriormente. Finalmente deve ser dada uma resposta à questão colocada no título e o leitor chegará ao final informado sobre o que o autor do documento considera ensaio teórico.

Devo declarar que partilho com o autor o seu entusiasmo pelo ensaio e lamento sua vulgarização, fazendo com que na comunidade acadêmica seja implicitamente colocado como forma não científica de abordar uma questão. O documento contém esforço, apelo e, no final, o desafio para que se recoloque o ensaio como forma absolutamente legítima de produção de conhecimento.

O ensaio tem posicionamento difícil enquanto modo de produção científica, devido à hegemonia da ciência positiva. O clássico trabalho de Kuhn (1970), onde é desenvolvida a noção de paradigma, como forma de explicar as transformações que ocorreram na produção e eventual acumulação de conhecimento científico, explica grande parte da tendência de organizar a produção de conhecimento em termos de linhas de pesquisa (research tracks) e a consequente burocratização da ciência. A ciência de tipo positivo é mais confiável em termos de cumprimento de cronogramas e metas de produção e permite se computem índices de produtividade, tão do agrado das agências reguladoras. Quando digo confiável, me refiro ao procedimento metodológico de que, uma vez dominada a metodologia de trabalho, centrada em análise multivariada, e tendo-se à disposição bancos de dados, o pesquisador competente será capaz de dialogar com o banco e assim obter respostas para as hipóteses que vier a formular.

Se, por outro lado, a opção for por trabalho de campo, onde se coletam informações, estaremos também em limites muito mais seguros do que aqueles que se apresentam ao autor de um ensaio teórico, ou simplesmente de qualquer tipo de ensaio. No limite, diria que, se o pesquisador nada tiver de relevante, novo ou rejuvenescedor a dizer, falará sobre seus dados ou achados; assim, o trabalho será feito e todos caminham para um final feliz. Felizes ficarão o autor, o programa de pós-graduação, a agência reguladora e os periódicos que continuarão com longas filas de textos aguardando avaliação e publicação. Mas se encaramos o ensaio, as coisas se alterarão substancialmente. No ensaio temos apenas o ensaísta com suas ideias, sua bagagem de cultura e conhecimentos e a reflexão acumulada sobre o tema que escolheu abordar.

As características do ensaio ajudam na explicação do porquê ele tendeu a ser preterido por produções científicas que adotam o modelo da ciência positiva. O ensaio é fundamentalmente difícil. Não há como salvar um mau ensaio. Mas é possível resgatar trabalhos que, embora não contribuam para descoberta e acumulação de conhecimento, como acontece com a maioria dos produtos científicos contemporâneos, podem merecer elogios pelo rigor e criatividade metodológica.

Acredito que a dificuldade encontrada pelo ensaio como forma de produção científica em ciências sociais, onde a administração se insere, está fundamentalmente ligada ao triunfo da ciência de tipo positivo. Sob este aspecto, o provocativo texto de Francis K. Meneghetti permite que até se 
especule sobre se o futuro do conhecimento ainda reservará um lugar para formas de conhecimentos que não sejam literalmente conduzidos e formatados como ciência positiva. Não se pode deixar de lado a ponderação de que em nossos dias encontramos até filósofos que vêm sombriamente o futuro de sua própria disciplina, o que é pelo menos insólito.

Mas é oportuno insistir em que ao longo da história o ensaio foi a forma preferencial de exposição de ideias, teorias e posições filosóficas e que nosso imenso patrimônio cultural é constituído principalmente por ensaios. Tomemos como referência textos considerados marcantes ou clássicos na interpretação de nosso país. Livros como Raízes do Brasil (Buarque de Holanda, 1997), Casa Grande e Senzala (Gilberto Freire, 2006), Os Sertões (Euclides da Cunha, 2000), O Povo Brasileiro (Darcy Ribeiro, 1995), A Revolução Burguesa no Brasil (Florestan Fernandes, 2006) e constatamos que são todos ensaios. Sou tentado a registrar o que considero uma obra prima do gênero, $O$ Labirinto da Solidão (Octavio Paz, 2006) sobre a cultura mexicana.

$\mathrm{Na}$ área de administração muitas contribuições na área tiveram a forma de ensaios. Lembremos autores como Peter Drucker, cuja obra é ensaística. O homem considerado até hoje o pai do management fugiu inteiramente à tradição da educação em administração norte-americana. Oriundo da Áustria, e pertencendo a uma geração que ainda não necessitava de titulação propiciada por mestrados e doutorados, teve uma produção que nunca se dirigiu aos periódicos considerados científicos da área. Contribuições originais de Drucker para a administração, como o conceito de Management by objectives (MBO), organizações intensivas em conhecimento knowledge intensive organizations, o trabalhador do conhecimento (knowledge worker), foram todos conceitos e ideias desenvolvidos e comunicados sob a forma de ensaios. Se tomarmos ainda o conhecido artigo de James March (1991), em que faz a distinção entre exploration e exploitation e seu conhecido conceito de garbage can (Cohen \& March, 1972), encontramo-nos também diante de ideias que fizeram avançar a área e que foram produzidos na forma de ensaios. Se nos voltamos para a área de estratégia empresarial, constataremos que o que hoje se conhece como Resource Based View (RBV) foi o resultado de uma série de ensaios, a começar pelo clássico artigo de Coase (1937) sobre a teoria da firma.

Se levantarmos a incômoda questão de saber o que ficará para o futuro, como conhecimento merecedor de atenção, em prazo mais longo, da imensa produção científica veiculada em nossos periódicos qualificados, a resposta não será reconfortante para os que se preocupam com questões epistemológicas. Se utilizarmos a metáfora de um núcleo, em que se encontram os conceitos fundamentais e teorias que conferem estabilidade e legitimidade a uma ciência ou área de conhecimentos, veremos que o núcleo muda pouco, tendendo a se manter relativamente estável ao longo do tempo. Poderá mudar, mas desde que haja o tipo de mudança que Kuhn chamou de mudança de paradigma. Ao redor deste núcleo central há uma miríade de produtos científicos que estão mais ou menos próximos do núcleo central. Á medida que nos afastamos do núcleo, o impacto diminui e consequentemente a relevância. Saber como produtos passam dos círculos concêntricos para o núcleo é questão interessante e provocadora. Mas certamente a maioria do que é produzido está destinada a gerar pouco ou nenhum impacto, sendo relegada ao esquecimento. Possivelmente muitas das ideias, conceitos fundamentais e teorias que integram o núcleo tiveram origem na forma de ensaios, já que o gênero não se restringe a nenhuma área ou ciência específica.

O corpo do documento de Francis Meneghetti contém observações epistemológicas oportunas, retiradas de vários autores que se ocuparam do ensaio enquanto forma e instrumento de conhecimento. Uma delas que gostaria de comentar é que o ensaio levaria à superação de uma dicotomia sujeito/objeto, clássica na teoria do conhecimento. Não sei exatamente, e a menos que não tenha entendido exatamente o que foi escrito, como se pode analisar o fenômeno do conhecimento sem levar em consideração a dicotomia sujeito/objeto. $\mathrm{O}$ fato de que no ensaio pode haver uma interiorização do objeto pelo sujeito não faz contudo que se elimine a dicotomia. Adicionaria que esta dicotomia é um elemento enriquecedor do ensaio, porque cria para o sujeito um espaço de liberdade para tratamento do objeto, que não existe nos cânones da ciência. A ciência naturalmente tem regras e a adesão ao cânone é imprescindível para que um conhecimento seja considerado científico. Não é isto que ocorre com o ensaio. Ele dispensa provas, no sentido de comprovações empíricas em que hipóteses são submetidas a testes. Sua coerência e sua legitimação residem na coerência das elaborações do ensaísta. 
Mas nada disto implica superação da dicotomia sujeito/objeto. Ela permanece e é um dos elementos enriquecedores do ensaio.

Elemento importante que não me parece tenha sido enfatizado pelo autor do documento foi a dimensão intuitiva do ensaio. O ensaio não é situado na antiguidade. $\mathrm{O}$ apogeu do pensamento clássico grego, nomeadamente de Platão e Aristóteles, não reserva lugar para o tipo de conhecimento que seria obtido com o ensaio. $\mathrm{O}$ que ambos almejavam era a episteme que representaria o universal, não transitório, e portanto geral. $\mathrm{O}$ singular, o individual era entendido como caminho para chegar-se à episteme, mas fixar-se no particular seria limitar-se à doxa (opinião). $\mathrm{O}$ ensaio surge com a idade moderna. A referência a Michel de Montaigne é relevante e apropriada. O ensaio afasta-se do universo clássico, ao encantar-se tanto pelo universal como pelo particular. O ensaio é a oportunidade de elaborar o particular, o singular, mas dotando-o sempre de relevância que possa encantar a Inteligência, seduzindo o leitor. Mas não existe metodologia para o ensaio, como existe para o conhecimento sob a forma de ciência positiva. Tentar elaborar uma metodologia do ensaio implicaria construtivismo que penetrasse na cabeça do ensaísta. E se tal jornada fosse empreendida, o que encontraríamos seria o misterioso fenômeno da intuição. Na verdade intuir é penetrar sem etapas mediadoras. Intuição é conhecimento imediato, sem a necessária progressão por etapas que caracterizava a episteme grega ou os processos indutivos ou dedutivos da ciência moderna. No universo platônico, a intuição seria a nôesis. A sequência platônica é a eikasia, ou seja, o mundo das imagens e percepções fugidias e necessariamente o singular e particular. Em seguida viria a doxa, ou o mundo das opiniões, mas que, por apoiarem-se ainda nas imagens da eikasia, tem caráter necessariamente arbitrário. Após temos a episteme, que se vale da contribuição pitagórica e que é o ápice do conhecimento, à exceção da nôesis, que nos coloca frente a frente com as idéias puras, universais e, como tal, incluindo ainda a justiça e a bondade. A nôesis é o conhecimento que se adquire pela contemplação das idéias ou dos conceitos ou formas em seu estado puro. Segundo a metáfora platônica do mito da caverna, a nôesis é o conhecimento dos que lograram deixar a caverna, onde contemplavam sombras e que tivessem saído para ver a luz solar iluminando as coisas reais e não as sombras projetadas. Analogamente, a nôesis é a intuição das formas perfeitas, que são apenas sugeridas pela experiência empírica.

Se adentrássemos o processo criativo ou de elaboração do ensaio, encontraríamos intuições decisivas que levaram o autor a produzi-lo. Isto não significa que intuições não sejam elaboradas e que um ensaio contenha raciocínios que usem da mediação indutiva e dedutiva. Vou valer-me de comparação com a composição musical. Naturalmente há muitas regras de composição musical, que se foram acumulando ao longo dos séculos. E todo compositor, em princípio, deve conhecer estas várias regras da composição. A melodia pode ser entendida como dado de intuição. $\mathrm{O}$ que atrai a maioria dos ouvintes para uma peça musical é sua linha melódica. A linha melódica nos seduz, nos enfeitiça. São, na verdade, enunciadas por sereias. Mas melodia não é obra musical. Se tal fosse, grandes melodistas estariam colocados necessariamente como grandes compositores, o que não acontece. Intuir melodia pode ser fundamental; mas a pergunta que segue é exatamente esta: Que fazer com ela? O grande compositor, à semelhança do grande ensaísta, é capaz de tomar uma melodia, ou várias e mesclá-las, elaborá-las em vários formatos, utilizando a riqueza de sons e timbres, propiciados pelos diversos instrumentos da orquestra.

Portanto não pode haver ensaio sem que ocorram intuições decisivas na mente do ensaísta. Na criação do ensaio, é possível elaborar sketchs, rascunhos ou outlines. Estas palavras são usadas como sinônimos. Todo ensaísta planeja o que vai escrever. Todavia isto não elimina o que se poderia chamar de caráter dialético do ensaio, ou seja, algo que se faz na marcha, ou à medida que o próprio ensaio é elaborado. Outline ou sketch é guia, registro de intuições que o ensaísta deseja registrar, mas não contém necessariamente o que será o ensaio acabado. Apesar do sketch, o percurso contém riscos e, muitas vezes, o ensaio acabado pode se afastar do sketch inicial.

No seu entusiasmo pelo ensaio, Francis Meneghetti nos convida a empreender um ensaio teórico. Entusiasmo compreensível, mas grande imprudência, simplesmente porque empreender um ensaio teórico não é para todos, nem para muitos, mas está reservado a poucos. O apelo de Francis Meneghetti poderia ser imprudente, em especial pelo que a maioria das pessoas, em nossa comunidade 
científica de administração, entende por teoria e por ensaio teórico. Basta que se leiam nossos artigos e as teses e dissertações que são aprovadas por nós em bancas julgadoras. Elas sempre incluem uma parte chamada de teórica. O que lá encontramos é um primitivo e rudimentar copy and paste, cujos méritos devem ser creditados mais à Microsoft, Bill Gates e certamente ao Google do que aos autores das teses e dissertações. Mesmo que as nossas chamadas revisões teóricas apresentassem bom resumo, devidamente articulado das idéias e teorias de vários autores ou escolas, ainda estaríamos distantes do que seria ensaio teórico.

O ensaio teórico deverá conter, necessariamente, se não o esboço de uma teoria, pelo menos algumas intuições que the confiram originalidade e criatividade. Dos diversos dons que possamos receber, o de ser teórico é muito raro. Por isso a maioria da produção científica não é nem poderia ser teórica. Poucos são suficientemente dotados para gerar teorias sob a forma de ensaios teóricos. Diria, com alguma crueldade, que a maioria de nós completa sua jornada neste planeta sem jamais ter tido uma idéia própria ou original. Muitas vezes, se consegue grande sucesso, particularmente na academia, repetindo, não necessariamente com brilhantismo e capacidade, as ideias e teorias dos outros.

Se tomarmos um livro que tem sido muito usado e referido na área de Estudos Organizacionais, refiro-me a The Sage Handbook of Organizational Studies (Clegg, Hardy, Lawrence, \& Nord, 2006), lá encontraremos um predomínio de capítulos que tem, no meu entender, a forma de ensaios teóricos. Todos implicam revisão da literatura; ele não repete o que foi dito pelos autores, mas procura apresentar o conhecimento acumulado, articulando-o com frequência sob nova luz. Além disso, são feitas críticas e abertas perspectivas para caminhos futuros, sugerindo eliminação de tendências e ênfase em tendências pouco exploradas ou ainda por explorar.

Fica no final desta réplica, que padece da dificuldade de ter de discordar daquilo com que se concorda, a esperança e a certeza de que o ensaio teórico não acabou com as grandes obras que já produziu. Resiste com bravura no momento de burocratização da produção científica sob a forma de trabalhos, com no máximo muito rigor, mas pouca ou nenhuma relevância. Fica a referência final, politicamente incorreta, que certas coisas não são para todos.

\section{Referências}

Clegg, S. C., Hardy, S., Lawrence, T. B., \& Nord, W. R. (2006). The sage handbook of organizational studies (2a ed.). Londres: Sage Publications.

Coase, R. H. (1937). The nature of the firm. Economica, 4(16), 386-405.

Cohen, M. D., March, J. G., \& Olsen, J. P. (1972). A garbage can model of organizational choice. Administrative Science Quarterly, 17(1), 1-25. doi: 10.2307/2392088

Cunha, E. (2000). Os sertões. São Paulo: Publifolha.

Fernandes, F. (2006). A revolução burguesa no Brasil. Rio de Janeiro: Editora Globo.

Freire, G. (2006). Casa grande e senzala. Rio de Janeiro: Global Editora.

Holanda, S. B. de (1997). Raízes do Brasil. São Paulo: Companhia das Letras.

Kuhn, T. (1970). The structure of scientific revolutions (2a ed.). Chicago: University of Chicago Press.

March, J. G. (1991). Exploration and exploitation in organizational learning. Organization Science, 2(1), 71-87. doi: $10.1287 /$ orsc.2.1.71

Paz, O. (2006). O labirinto da solidão e post scriptum. Petrópolis: Paz e Terra.

Ribeiro, D. (1995). O povo brasileiro. São Paulo: Companhia das Letras. 